\title{
Análise do grau de satisfação dos contratantes de serviços terceirizados na modalidade BPO - Business Process Outsourcing - na Grande São Paulo
}

\section{Analysis of the satisfaction level of services contractors in BPO - Business Process Outsourcing Method - in Sao Paulo metropolitan area}

\author{
Ivam Ricardo Peleias \\ Doutor e Mestre em Ciências Contábeis pela FEA- \\ USP; Professor e Pesquisador Contábil do Centro \\ Universitário FECAP e da Pontifícia Universidade \\ Católica de São Paulo - PUC- SP \\ ivamrp@fecap.br
}

\section{Geuma Campos Nascimento}

Mestre em Ciências Contábeis pelo Centro Universitário FECAP; Professora da Trevisan Escola de Negócios geuma.nascimento@tgec.com.br
Contextus

SSNe 2178-9258

Organização: Comitê Científico Interinstitucional Editor Científico: Marcelle Colares Oliveira Avaliação: Double Blind Review pelo SEER/OJS Revisão: Gramatical, normativa e de formatação Recebimento: 20/03/2013 Aprovação: 26/12/2013

\section{Claúdio Parisi}

Doutor e Mestre em Ciencias Contábeis pela FEA USP; Professor e pesquisador contábil do Centro Universitário FECAP

claudio.parisi@uol.com.br

\section{RESUMO}

Buscou-se analisar as percepções dos gestores de empresas da grande São Paulo, contratantes de serviços na modalidade BPO - Business Process Outsourcing. É uma investigação descritiva e qualiquantitativa, cujos dados foram coletados em duas etapas, com entrevista de profundidade e questionário. Os dados obtidos com as seis entrevistas e os documentos foram tratados com a análise de conteúdo, oferecendo subsídios para a sequência da investigação. Os dados obtidos com os 23 questionários foram tratados com a análise de clusters. Constatou-se que $74 \%$ dos respondentes declararam-se satisfeitos com os serviços recebidos quanto à qualidade, prazos atendidos e confiabilidade sobre a qualificação técnica do prestador de serviços. Os respondentes concordam que prestadores e tomadores dos serviços realizam a gestão dos contratos e que a assimetria informacional não tem afetado de forma negativa a relação contratual. Identificou-se a necessidade de outras pesquisas sobre a terceirização de serviços administrativos e financeiros.

Palavras-chave: Assimetria informacional. Clientes. Contratos. Gestão de contratos. Serviços. Terceirização de processos de negócios $(B P O)$.

\section{ABSTRACT}

The aim of this article was to analyse the managers' perceptions of companies in São Paulo, who hire administrative services in the Business Process Outsourcing - BPO method. It was a descriptive and quali-quantitative research; the data collection was made in two steps, using the questionnaire and an in depth interview. The data collected in the six interviews and the documents were treated by means of the content analysis, as to guarantee the research continuity. The data obtained with the 23 questionnaires were treated through the cluster analysis. It was verified that $74 \%$ of the subjects are satisfied with the services they receive concerning quality, deadline and trustfulness regarding the technical qualification of the services provider. The subjects agreed that services hirers and providers do manage the contracts and that the informational asymmetry is not negatively affecting the contractual relationship. It was stated the need for more research about the outsourcing of administrative and financial services.

Keywords: Information asymmetry. Clients. Contracts. Contracts management. Services. BPO. 


\section{INTRODUÇÃO}

A atuação das empresas no cenário dos negócios requer que, em algumas situações busque-se auxílio externo especializado. Uma forma é a identificação e contratação de prestadores de serviços para atividades de retaguarda, que não integram o core business da organização. A prestação desses serviços requer formação e conhecimentos específicos, oferecidos por organizações especializadas.

Este é o cenário no qual as empresas dedicadas à terceirização das áreas administrativas e financeiras (business process outsourcing-BPO) identificam oportunidades de negócios e oferecem seus serviços. Diante das necessidades de contratantes e das oportunidades para ofertantes, constata-se no Brasil o crescimento no uso de serviços técnicos especializados, executados por prestadores externos (SINDESPRESTEM, 2008).

A terceirização (outsourcing) é a ação exercida por uma organização na obtenção de mão-de-obra de terceiros. A contratação de prestadores de serviços nessa modalidade encontra-se razoavelmente difundida em muitas organizações. Ocorre quando uma organização faz a gestão não otimizada em um particular processo do seu negócio (por exemplo: contabilidade ou folha de pagamento) e o repassa a uma terceira parte. A premissa é de que a contratação permita que o tomador dos serviços dirija esforços para sua atividade principal (BROWN; WILSON, 2005; PAIVA, SOUZA, 2011).

A terceirização não é novidade no cenário empresarial. Greaver II (1999), Giosa (1997) e Pagnoncelli (1993) relatam seu surgimento após o início da II Guerra Mundial, quando as indústrias bélicas norte-americanas passaram a delegar atividades para prestadoras de serviço, concentrando-se no desenvolvimento e na produção de armamentos.

Há cerca de meio século a terceirização integra a realidade de empresas brasileiras e de outras que se instalaram no País. Iniciou-se nos anos 1960, com a vinda de multinacionais, principalmente do setor automobilístico, que adquiriam seus componentes de vários fornecedores, concentrando-se na atividade primária, a montagem dos veículos.

A terceirização no Mundo e no Brasil vem alcançando crescimento contínuo e sistemático. Pesquisa da A.T. Kearney (IDG NOW, 2009) mostra que o Brasil avançou cinco posições entre 2005 e 2007, ocupando hoje a $5^{\mathrm{a}}$ posição mundial dos Países com desenvolvimento de negócios na modalidade offshore outsourcing. 
Na década de 1990, foi publicada a Súmula de $\mathrm{n}^{\circ} 331$ pelo Tribunal Superior do Trabalho (TST) (BRASIL, 2006), tratando da prestação de serviços terceirizados. Desde então, vêm ocorrendo discussões no País. Há, no Congresso e, em entidades de classe, grupos dedicados aos vários aspectos desta prática de negócio. Após atravessar todas as discussões, será preciso constituir um modelo jurídico para mitigar os obstáculos levantados sobre a prática da terceirização.

Outro aspecto que envolve a relação contratual entre tomadores e prestadores de serviços na modalidade BPO é o necessário conhecimento mútuo entre as partes. Isto requer o estudo das relações contratuais e em que medida poderá ocorrer eventual assimetria informacional entre as partes.

Esse é o cenário de realização da pesquisa, com a qual busca-se resposta à seguinte pergunta: Qual é a percepção dos gestores das empresas contratantes de serviços administrativos e financeiros (business process outsourcing-BPO) sobre a prestação desses serviços?

O objetivo geral foi analisar quais são as práticas de gestão de contratos entre prestadores e tomadores de serviços e o grau de satisfação destes. Os objetivos específicos foram: analisar o modelo e a relação contratual entre prestador e tomador dos serviços, além de analisar a percepção dos gestores das contratantes em relação aos serviços tomados.

Há trabalhos sobre a terceirização (ALVAREZ, 1996; BROWN; WILSON, 2005; GIOSA, 1997; MANI; BARUA; WHINSTON，2005; OLIVEIRA，1994; PAGNONCELLI, 1993), inclusive para setores específicos

(BANDEIRA; MELLO; MAÇADA, 2012; LUCIANO; TESTA, 2011; PAIVA; SOUZA, 2012; SOUZA; MALDONADO; RADOS, 2011). Até o momento, não foram localizados estudos sobre a terceirização de serviços administrativos e financeiros e nem sobre a percepção dos gestores das empresas tomadoras desses serviços. Busca-se contribuir com os interessados na temática "serviços terceirizados", procurando revelar e analisar características da relação contratual entre prestador e tomador na grande São Paulo.

\section{FUNDAMENTAÇÃO TEÓRICA}

\subsection{Serviços: Definição e Características Relevantes}

A venda de um serviço é um compromisso para entrega de algo intangível, perceptível com a prestação e o recebimento de algo eventualmente insinuado, falado ou escrito em contrato, cuja natureza e definição podem ser 
consideradas sob diferentes perspectivas.

Os serviços requerem interação entre prestador e cliente, além de do que podem estar relacionados a produtos. Para Grönroos (2004), quando o cliente escolhe a cor e os equipamentos para seu carro novo, ele participa da produção dos serviços pois decidiu sobre estes atributos a serem incluídos no veículo.

Grönroos (2004) apontou três características dos serviços: a) são atividades ao invés de coisas; b) são, até certo ponto, produzidos e consumidos simultaneamente; c) até certo ponto, o cliente participa da sua produção. Grönroos (2004), alerta que entre as décadas de 1960 a 1980, surgiram muitas definiçõos para o termo "serviço". Identificou na obra de Gummesson (1991) uma definição de fonte não identificada: "um serviço é algo que pode ser comprado e vendido, mas, que não se pode derrubar nos pés".

Estudiosos do segmento propõem definições especificas para o termo "serviço", nas quais destacam características que consideram relevantes, como demonstrado no quadro 1.

Quadro 1 - Definições de serviços

\begin{tabular}{|c|c|}
\hline Autores & Definições \\
\hline $\begin{array}{l}\text { Kotler; } \\
\text { Bloom } \\
(1988, p \text {. } \\
\text { 190) }\end{array}$ & $\begin{array}{l}\text { Qualquer atividade ou benefício que uma parte possa oferecer a outra, que seja essencialmente } \\
\text { intangível e não resulte na propriedade de qualquer coisa. Sua produção pode ou não estar } \\
\text { vinculada a um produto físico. }\end{array}$ \\
\hline $\begin{array}{l}\text { Normann } \\
(1993, p \text {. } \\
\text { 62) }\end{array}$ & $\begin{array}{l}\text { Um processo social, no qual a essência é a habilidade de sua administração. As organizações de } \\
\text { serviços são mais sensíveis à qualidade de sua administração do que provavelmente qualquer } \\
\text { outro tipo de organização. }\end{array}$ \\
\hline $\begin{array}{l}\text { Lovelock, } \\
\text { Wright } \\
(2001, \text { p. } \\
\text { 5) }\end{array}$ & $\begin{array}{l}\text { Um ato ou desempenho que cria benefícios para clientes por meio de uma mudança desejada no } \\
\text { - ou em nome do - destinatário do serviço. }\end{array}$ \\
\hline $\begin{array}{l}\text { Grönroos } \\
(2004, p . \\
\text { 65) }\end{array}$ & $\begin{array}{l}\text { Um processo, consistindo em uma série de atividades mais ou menos intangíveis que, } \\
\text { normalmente, mas não necessariamente sempre, ocorrem nas interações entre o cliente e os } \\
\text { funcionários e/ou recursos ou bens físicos e/ou sistemas do fornecedor de serviços e que são } \\
\text { fornecidas como soluções para problemas do cliente. }\end{array}$ \\
\hline
\end{tabular}

Fonte: os autores.

Serviços são prestados e distribuídos para o consumo final. São de difícil controle, muitas vezes sem tempo prévio para a aferição dos padrões de qualidade antes da entrega ao cliente. Normann, (1993) aponta três características da "indústria de serviços": (a) intangibilidade (oposta à materialidade dos bens) - não podem ser estocados, facilmente demonstrados e, quando vendidos, pode não ser necessária a transferência de posse; (b) a maioria dos serviços requer ações e interações sociais, pois o controle e a administração de eventos sociais exigem habilidades e técnicas especiais; (c) nem sempre se pode 
separar a prestação e o consumo de serviços, pois ocorrem no mesmo tempo e mesmo local. Frequentemente o cliente é mais do que consumidor - participa da produção do serviço.

Quadro 2 - Diferenças entre os serviços e bens físicos

\begin{tabular}{|c|c|}
\hline Bens & Serviços \\
\hline Tangíveis & Intangíveis \\
\hline Homogêneos & Heterogêneos \\
\hline Valor central produzido na fábrica & $\begin{array}{c}\text { Valor central produzido nas interações entre comprador e } \\
\text { vendedor }\end{array}$ \\
\hline
\end{tabular}

Fonte: Adaptado de Grönroos, (2004, p. 66)

Lovelock e Wright (2001, p. 17) asseveram que a intangibilidade do serviço ocorre por experimentação, sem ser tocado ou preservado. Os autores ampliam estas características ao afirmarem que os clientes não obtêm propriedade sobre os serviços. Os serviços geram realizações intangíveis, os clientes e outras pessoas se envolvem na sua realização. Há maior variabilidade nos insumos operacionais, os serviços são de difícil avaliação pelos clientes, o fator tempo é importante e os sistemas de entrega podem envolver canais eletrônicos e físicos.

Grönroos (2004), discorda que a intangibilidade seja a característica relevante do serviço, pois, nem sempre bens físicos são tangíveis para os clientes. Relata que a compra de tomates ou de um carro podem ser percebidos de modo subjetivo e intangível por distintos compradores. Exemplifica a tangibilidade dos serviços prestados com elementos tangíveis (comida em restaurante;
Grönroos, (2004) sugere complementos às características dos serviços, em comparação aos bens físicos, como se vê no quadro 2. documentos usados por empresas de entregas; peças de reposição no reparo de bens). Porém, reconhece que a intangibilidade da essência dos serviços. A confirmação ocorre quando o cliente descreve um serviço com palavras subjetivas e intangíveis: experiência, confiança, sentimento e segurança.

A mitigação da intangibilidade dos serviços requer comprovação e que o cliente perceba as evidências cedidas pelo prestador. Berry (1980) ilustra a comprovação com evidências de manuseio e sugere atitudes ao prestador de serviços: a) evidência física: a sede e as instalações do prestador; a papelaria à disposição do cliente e a proposta ou contrato apresentado; b) aparência: os profissionais podem ser "embalados": vestimenta, postura, atitude e conhecimento, para encantar e transmitir ao cliente o quão tangível é o serviço a ser prestado; e c) após coordenar os atributos para encantar o contratante, o prestador estabelece preços 
mais justos, pois com a qualidade esperada e recebida pelo cliente, este pode não ter o preço como referencial principal para continuar usando os serviços. A supremacia da qualidade em relação ao preço constatada por Sá, Bomtempo e Quental (1998) é uma variável para o tomador dos serviços.

Alguns fatores podem ser atributos de tangilibilidade para o cliente, como a marca e a especialização pelos anos de existência da prestadora. As organizações de serviços não se destacam apenas pela existência singular dos três elementos seguintes: porém, Gianesi e Correa (1994) recomendam aos prestadores que neles invistam: a) evidência física - devido à intangibilidade, os consumidores podem basear sua avaliação na porção tangível do pacote de serviços, a priori ou a posteriori: instalações, pessoas, equipamentos ou bens facilitadores; b) a atitude e o comportamento dos participantes - as pessoas que prestam o serviço, funcionários ou outros consumidores, afetarão o sucesso do serviço e a avaliação do consumidor; e c) processo - tem papel mercadológico fundamental pois, em função da participação do consumidor, muitas vezes o processo é mais importante para a avaliação do que o próprio resultado.

A variabilidade do serviço se dá pela falta de consistência nos insumos durante a sua prestação (LOVELOCK, WRIGHT, 2001). Uma característica dos serviços é esta variabilidade, que ocorre na forma de cada prestador atender uma demanda, mesmo que seja do mesmo tipo de serviço.

Um exemplo é o trabalho de consultoria tributária, executado pelo colaborador de um prestador em relação a outro. Cada prestador tem sua essência e cada colaborador seu tem singularidades na realização das tarefas, mesmo que de forma padronizada.

A variabilidade dos serviços tem aspectos positivos e negativos. Um aspecto negativo, a partir do exemplo acima, é que dificulta a mensuração exata para a avaliação pelo contratante. Mesmo que o responsável pela tarefa siga um padrão ou "cartilha", pode interpretá-la de forma diferente, vindo a prejudicar a qualidade estabelecida pelas partes.

Quando a variabilidade obtém vultos não gerenciais para os prestadores e contratantes dos serviços é difícil estabelecer um padrão possível de embutir métricas de mensuração da performance global do negócio, tornando os erros acentuados e repetitivos. Uma consequência desta variabilidade é que a qualidade do serviço depende das pessoas que o prestam e da percepção dos que o consomem. 
Um desafio dos prestadores e dos usuários é conseguir, mesmo com a existência da variabilidade, estabelecer padrões para uma performance adequada ao serviço e que corresponda às expectativas das partes. Ao corroborar com a especificação de heterogeneidade na prestação de serviços, Grönroos, (2004) afirma que esta cria um problema no gerenciamento: o de manter uma qualidade uniformemente percebida dos serviços prestados aos clientes.

A heterogeneidade assume seu formato, pois os processos possuem atividades, tarefas e, para cada célula (processo, atividade e tarefa), há requisitos de qualidade, prazo e custos atribuídos que podem ser usados para avaliar o prestador. Este aspecto dificulta a decisão de compra, pois, nem sempre a padronização é percebida pelo cliente neste momento.

$\mathrm{Na}$ terceirização a perecibilidade ocorre quando o prestador tem profissionais para atender uma demanda superior à capacidade de produção dos indivíduos. Entretanto, as instalações necessárias (espaço físico, máquinas, conhecimento em materiais desenvolvidos para serviço prestado, telefonia, dentre outros) para atender uma demanda superior, são mantidas. Segundo Lovelock e Wright (2001) isto é a capacidade produtiva e não o próprio serviço.
Os serviços são perecíveis e não podem ser estocados para uso posterior, o que os torna temporais, prestados num espaço de tempo e local precisos. Um desafio dos prestadores é a administração da demanda versus a oferta na medida exata para encontrar o ponto ótimo entre estas duas variáveis. $\mathrm{O}$ desequilíbrio entre as variáveis pode ocorrer em dois cenários: a) não atender o excesso de demanda em tempo hábil a não prejudicar a imagem do prestador; e b) suportar custos desnecessários de atividades operacionais e de retaguarda (administrativas e financeiras), por não haver a demanda necessária para a capacidade produtiva.

Os atributos descritos, específicos do setor de serviços, conduzem a uma reflexão sobre elementos que fortalecem a "tangibilidade" para que o usuário perceba a qualidade. Os serviços são idéias e conceitos; não são patenteáveis e o consumidor baseia-se na reputação da marca ou do serviço que está comprando. Estes elementos são descritos a seguir.

As instalações de apoio são os recursos físicos, instalações $\mathrm{e}$ equipamentos, necessários à prestação dos serviços; os bens facilitadores são os materiais consumidos, adquiridos ou fornecidos ao consumidor; o serviço explícito é o benefício percebido pelos sentidos, considerados características 
essenciais do serviço; e serviço implícito são os benefícios psicológicos ou características acessórias do serviço. (GIANESI; CORRÊEA, 1994).

Empresas podem contratar prestadores de serviços para suas atividades meio, praticando a terceirização, a seguir apresentada.

\subsection{Terceirização}

Empresas terceirizam atividades por várias razões. A organização é eficaz quando se concentra em uma tarefa (DRUCKER, 1999). A diversificação destrói a capacidade de desempenho de empresas, sindicatos, escolas, hospitais ou igrejas. Sociedade e comunidade devem ser multidimensionais; elas são ambientes. Uma organização é como uma ferramenta e, como tal, quanto mais especializada for, maior sua capacidade para realizar a tarefa.

A sobrevivência da empresa depende das decisões de seus gestores, o que requer o uso das melhores práticas e ferramentas de gestão. Vidal Neto (1992) assevera que a terceirização real é uma forma moderna e aperfeiçoada de organização empresarial, permitindo maior eficiência administrativa e aprimoramento qualitativo, que não é marchandage ou contratação de mão-de-obra por interposta pessoa e não logra aviltar a remuneração ou deteriorar as condições de trabalho. É uma atividade econômica, desenvolvida livremente, respaldada no $\S$ único do art. 170 da Constituição Federal: "É assegurado a todos o livre exercício de qualquer atividade econômica, independentemente de autorização de órgãos públicos, salvo nos casos previstos em lei” (BRASIL, 1988).

Vidal Neto (1992) descreve as diferentes formas de contratação. A terceirização é a transferência de atividades "non core business", enquanto a alocação de mão-de-obra é a compra de trabalho temporário para atividades em períodos curtos. A marchandage (indústria de empreiteiros, ou uma convenção de subempreitada) é qualificada por alguns juristas como a falsa contratação. É a compra da força de trabalho, para, assim, revender ao empresário.

A formulação de uma definição para a terceirização pode parecer simples, mas não é consensual. Marcelino e Cavalcante (2012) relatam que o termo é objeto de estudo em várias disciplinas e que, em cada uma delas, há controvérsias em torno de sua definição.

Friedman (2007) assevera que o outsourcing ocorre quando uma empresa terceiriza funções realizadas por seus empregados (pesquisa, call center ou cobrança), com a contratação de outra para realizá-las, em seguida reintegrada às suas operações. $\mathrm{O}$ autor diferencia o outsourcing do offshoring. Este ocorre 
quando uma empresa transfere uma fábrica de Canton, Ohio, para Cantão, na China. Lá, produzirá o mesmo produto, da mesma maneira, com mão-de-obra mais barata, carga tributária menor, energia subsidiada e menos gastos com os planos de saúde dos funcionários.

A atividade-fim diz respeito aos objetivos da empresa, incluindo a produção de bens ou serviços. A comercialização é uma atividade central, de seu objeto social. Para o Direito Comercial, atividade-fim ou principal é a que consta do objeto do contrato social. A atividade-meio não coincide com os fins principais. É não essencial, secundária, não é seu objeto central. É de apoio ou complementar (MARTINS, 2005).

Vários fatores afetam a compra e a venda de serviços, caracterizando um contrato de terceirização. É preciso tempo, esforço e conhecimento para estabelecer uma relação duradoura. Requer foco e dedicação das partes para que não haja desgaste e descontinuidade. As partes devem atender aos preceitos da Legislação Comercial e a outros aspectos (custos, empregados de ambos os lados, métricas, entre outras), reveladores de cuidados pelos sujeitos da relação contratual.

Oliveira (1994) assevera que é fácil entender que os empregados, na maioria das empresas do País, são avaliados pela sua lealdade pessoal aos empregadores. De um terceiro espera-se impessoalidade, profissionalismo e cumprimento das responsabilidades contratuais. Certas áreas das empresas são terceirizadas para baixar custos. Os empresários brasileiros certamente o fazem também na expectativa de praticar uma gestão mais profissional e menos "emocional" ou "familiar".

Pagnoncelli (1993) aponta 11

diferentes armadilhas da terceirização:

- o "canto da sereia" da redução de custos, baixando a qualidade do produto ou serviço quando a terceirização não for planejada;

- "deixa que eu faço, sai mais barato" - nem sempre o mais barato é o mais seguro;

- é preciso avaliar quais áreas requerem sigilo, para protegê-las com termos jurídicos;

- alguns executivos temem a terceirização por diminuir sua equipe direta e seu poder;

- estrutura monstruosa para controlar os terceiros, isso depende da forma de controle;

- a má escolha dos terceiros pode causar atendimento ruim;

- "a dose é a diferença entre o veneno e o remédio" - cuidado com o que e com quem terceirizar; 
- evitar laços paternalistas com os terceiros, aceitando dependência econômica;

- há risco de a terceira arcar com o ônus das flutuações econômicas da contratante;

- o sindicalismo é um risco ao se olhar apenas os "uivos" sindicais e olvidar a legislação;

- a terceirização traz problemas legais quando a relação não se baseia em dispositivos legais que alcancem todos os aspectos da relação entre as partes.

Em contraponto às armadilhas, Alvarez (1996) relata cuidados e ações do contratante em relação aos tipos de serviços e formas de recebimento desses:

- análise e definição cuidadosa de atividade-fim, ao terceirizar as áreas-meio;

- planejamento eficaz ao divulgar a decisão de terceirizar aos profissionais e stakeholders, inclusive aos sindicatos;

- a análise e decisão pela terceirização não visa apenas reduzir custos, que acontece com a efetividade de outros fatores (ganhos de produtividade com a especialização e inserção da tecnologia);

- avaliar a capacidade geral dos players;

- os termos contratuais devem ser precisos e claros para todos;

- cuidar da questão social das demissões, incentivando a transferência dos trabalhadores para o player, buscando o fim do vínculo empregatício;

- assegurar-se da qualificação do terceiro;

- na transição, cuidar do "treinamento da contratante" para o pessoal da contratada;

- evitar a exclusividade do prestador de serviços;

- realizar auditorias de qualidade garante a eficácia da relação contratual.

Os posicionamentos de Pagnoncelli (1993) e Alvarez (1996) revelam que a terceirização não mera alternativa à redução de custos internos. Os conceitos evoluíram e a terceirização pode ser uma estratégia para informatização, melhoria dos processos operacionais e sistêmicos e serviços compartilhados. Propicia ao tomador dos serviços maior flexibilidade e alternativas para suas estratégias de médio e longo prazo. 


\subsubsection{Terceirização de serviços} administrativos e financeiros

Foi preciso tipificar e classificar os serviços administrativos financeiros. Para o IBGE (2006), Os serviços terceirizáveis, administrativos e financeiros ou intermediários, são prestados por empresas do segmento às demais organizações por eles interessadas. As atividades de serviços técnico-profissionais - consultorias, agências de publicidade, escritórios de advocacia e contabilidade, serviços de engenharia e arquitetura - caracterizam-se pela oferta de serviços que exigem mãode-obra qualificada e especializada, reconhecidos pela literatura como intensivos em conhecimento.

Dados do IBGE (2006) revelam que os serviços objeto desta pesquisa tiveram destaque. Geraram, em 2006, uma receita operacional líquida de cerca $\mathrm{R} \$$ 51,8 bilhões, (48,2\% do total), em um universo de 119.506 empresas $(53,4 \%$ do total), com participação de $34,6 \%$ no total dos salários, retiradas e outras remunerações pagos no período.

$$
\text { Pesquisa da A.T.Kearney (IDG }
$$
NOW, 2009) revela que o mercado mundial de serviços offshore outsourcing atingiu 101 bilhões de dólares em 2009 $22,6 \%$ a mais do que em 2008. O Brasil poderá disputar metade desse valor com outras economias emergentes. O estudo revela que, para ser um dos três principais players globais em termos de destino de offshore, o Brasil deve cuidar da questão tributária nestes e nos próximos anos.

A evolução e o posicionamento do Brasil sobre a terceirização constam na pesquisa do Sindicato das Empresas de Prestação de Serviços a Terceiros, Colocação e Administração de Mão-deobra e de Trabalho Temporário no Estado de São Paulo (SINDESPRESTEM), no biênio 2007-2008. Esta pesquisa apontou que há no mundo cerca de 376,8 milhões de ocupações terceirizadas, $15,5 \%$ da mãode-obra em atividade plena. No Brasil há 7,1 milhões de trabalhadores terceirizados (1,9\% destas ocupações no mundo); $21,4 \%$ dos empregados com carteira assinada (33,2 milhões de trabalhadores) e 7,7\% da população economicamente ativa.

Os dados analisados permitem inferir que a terceirização de serviços é uma realidade irreversível do Brasil, como apontado pelo SINDESPRESTEM (2008). Para que a terceirização atinja os objetivos que dela se espera, é necessária uma relação contratual entre as partes, a seguir debatida.

2.3 Teoria dos Contratos e Gestão de Contratos de Terceirização

Ripert (1937) assevera que o contrato já não é ordem estável, mas eterno 
vir a ser e que o credor não possui um direito adquirido, mas a esperança de que o juiz tenha as suas pretensões como legítimas.Ripert (1937) acredita que o contrato é uma peça de pura incerteza, com probabilidades de se concretizar.

Fonseca (1995) destaca que o contrato não existe isoladamente, mas em um contexto, no interior de um conjunto normativo. $\mathrm{O}$ contrato parte do ordenamento jurídico e deve acompanhar o seu modo de inserção na sociedade de que é expressão. A evolução do ordenamento e do contrato segue o caminho das alterações havidas na sociedade, já que o Direito é uma expressão cultural.

Lopes (2004, p. 173) debate a teoria contratual da firma: "a empresa é vista como um conjunto de contratos entre os vários participantes. Cada participante contribui com algo para a firma e em troca recebe sua parte no bolo". Pressupõe-se a existência de acordos tácitos ou não entre o tomador e o prestador dos serviços. Este entrega os serviços ao comprador, que repassa uma quantia em moeda local equivalente ao previamente acordado em contrato.

Mas pode haver conflitos na relação. Lopes (2004) caracteriza a divergência como um conflito de agência e argumenta que a existência do conflito surge quando agentes ligados à empresa possuem interesses distintos e, ao priorizarem seus interesses pessoais, prejudicam a organização. Paiva e Souza (2012) propuseram um modelo de contrato que buscou induzir a cooperação entre principal e agente na obtenção de resultados positivos.

A existência do conflito entre prestador e tomador de serviços é fruto de divergências sobre questões não explicitadas no contrato ou ainda, que não houve a explicitação. Contudo, por serem sujeitos com interesses pessoais e profissionais distintos, tiveram leituras diferentes sobre a mesma temática. Adiante, será abordada a gestão do contrato de terceirização.

Tomada a decisão pela terceirização ( $1^{\text {a }}$ fase), inicia-se um ciclo

sequencial de estados de um sistema que se altera evolutivamente:

a) a $2^{\mathrm{a}}$ fase requer um plano detalhando fases e atores envolvidos - documentação oficial, registro do processo do negócio, análise dos ativos, avaliação dos riscos e gestão dos ativos tangíveis e intangíveis relativos à matéria terceirizável. Argyres e Mayer (2007) apontaram a necessidade de equipes multifuncionais para o desenho do contrato;

b) a $3^{\text {a }}$ fase é a escolha do player. Requer uma solicitação de proposta 
(Request For Proposal - RFP). A RFP é um sub-projeto da terceirização, que requer um líder conhecedor do projeto maior, desde a estratégia até o processo completo final, e que traga para dentro da RFP as diretrizes de forma padronizada e inviolável, para que a escolha do fornecedor ocorra na mesma base de dados, além de informações de todos os participantes. Aqui, é preciso definir o nível de serviços ofertado e esperado (Services Level Agreement - SLA) entre as partes;

c) a $4^{\mathrm{a}}$ fase é o momento da transição dos processos terceirizados, dos ativos tangíveis e intangíveis, se for o caso. Sua duração depende dos elementos quantitativos $\mathrm{e}$ qualitativos terceirizáveis. É ao final desta fase que se inicia a gestão do $S L A$;

d) a $5^{\mathrm{a}}$ fase permite a gestão plena do projeto, desde a revisão das conformidades e/ou inconformidades nos contratos firmados, até a gestão das matérias entregues versus a cobrança pelos serviços prestados/tomados, ou seja, se as métricas acordadas foram atendidas. Aqui, ocorrem as primeiras assimetrias informacionais oriundas das regras contratuais que, de alguma forma, têm características subjetivas e causam expectativas distintas para as partes;

e) a $6^{a}$ fase (não é a final, apesar de o ciclo indicar isso) retroalimenta o ciclo enquanto durar o contrato. Seus elementos são oxigenados por reuniões periódicas entre o gestor de contratos, o prestador, o gestor de contas e o tomador dos serviços, para alinhar expectativas mútuas e mitigar a assimetria informacional.

As fases descritas revelam o apontado por Bandeira, Mello e Maçada para a área de logística (2011, p. 239): que um contrato de terceirização possui duas funções distintas: coordenação e controle. A coordenação esclarece expectativas mútuas, delineia papéis, regras e procedimentos relativos ao esforço conjugado para atingir metas coletivas. $\mathrm{O}$ controle determina e influencia o que as partes farão.

Quanto ao ciclo do processo de $\mathrm{BPO}$, aos seus atributos e à satisfação do tomador dos serviços em relação a esses, Mani, Barua e Whinston (2005, p. 114) analisaram o trabalho de Sureshchandar et al. (2002) apud Mani, Barua e Whnston (2005, p. 114) e argumentaram que a satisfação do cliente deve ser desenvolvida ao longo dos mesmos fatores da qualidade do serviço. Adaptaram essa conceituação 
de satisfação do cliente para identificar quatro sub-constructos: confiabilidade, receptividade, responsabilidade e sistematização. Confiabilidade é a capacidade para executar o serviço prometido de forma confiável e precisa. Receptividade é a vontade para ajudar os clientes e fornecer o serviço de alerta. Responsabilidade é a responsabilização do prestador. Sistematização é a organização dos processos, procedimentos, de sistemas e tecnologia que fazem um serviço seamless (sem refazer, remendo, costura).

Um aspecto essencial para o sucesso da relação entre tomadores e prestadores de serviços na modalidade

BPO é a mitigação da assimetria informacional, último item da fundamentação teórica.

\subsection{Assimetria Informacional}

Os contratos implicam autoridade e definem rotinas a serem seguidas. Um contratante pode decidir pelos dois (num contrato bilateral), acelerarando o processo decisório (NOSSA, KASSAI, KASSAI, 2000). Para Whinston, Barua e Mani (2005), o contratante espera do prestador confiabilidade, receptividade, responsabilidade e sistematização. Isto requer do prestador atributos de atendimento e posicionamento mensuráveis e publicáveis, por meio de controles internos compreensíveis e aceitáveis pelas partes.

A relação de agência ocorre nos contratos em que o principal (tomador) contrata o agente (prestador) para executar um serviço a favor daquele, com base em alguma autonomia decisória necessária à prestação dos serviços (JENSEN; MECKLING, 1976). Essa relação de autonomias cedidas permite identificar a assimetria informacional entre as partes. Akerlof (1970), Spense (1973), Pauly (1974), Stiglitz e Weiss (1981), Gârleanu e Pedersen (2003), discutem a seleção adversa, a assimetria e simetria informacional. Adotou-se a proposição de Akerlof (1970), para o qual a assimetria informacional é uma característica das interações existentes nos mercados, em que os agentes, de um lado, têm informações melhores do que os agentes do outro lado do mercado.

Akerloff (1970) analisa o mercado americano de carros usados, em que os vendedores são mais bem informados do que os compradores sobre a qualidade do bem e os preços atribuídos a esse em função da qualidade. Nesse universo, pode haver $50 \%$ de bons carros e $50 \%$ de ruins, com a escala de preços diferente, estabelecida pelo vendedor. O comprador não conhece os atributos de qualidade como o vendedor e fica refém na hora de pagar o preço, com a crença de que a 
relação preço versus qualidade está em harmonia. Isso explica a dificuldade e a ineficiência do mercado e os esforços de empresas prestadoras de serviços para fidelizar seus clientes, pela entrega dos serviços e pelo conhecimento das suas expectativas e satisfação.

Hendriksen e Van Breda (1999) asseveram que a assimetria informacional ocorre quando nem todos os estados são conhecidos pelas partes e, assim, certas conseqüências não são por elas consideradas. É com essa crença que se busca verificar a existência de assimetria informacional na relação entre prestador e tomador na modalidade BPO, e o quanto essa pode afetar a confiança e satisfação dos tomadores desses serviços.

\section{METODOLOGIA E LIMITAÇÕES DA PESQUISA}

A pesquisa é não censitária, com uma amostra por acessibilidade, de acordo com a caracterização das empresas, o perfil e o grau de autonomia dos respondentes em cargos de decisão. Buscou-se um grau significativo de variação nas percepções sobre os serviços contratados junto às empresas de BPO. Foram escolhidas empresas e gestores descritos no quadro 1. Buscou-se, na identificação dos gestores, comprovar a autonomia de comprar e/ou a responsabilidade direta pelos serviços contratados.

É descritiva, baseada em pesquisa documental. Na coleta dos dados foram usadas a entrevista de profundidade e o questionário (HAIR JR et al.AL, 2005; HILL, HILL, 2005). Os dados foram obtidos em duas fontes distintas: na $1^{\text {a }}$ etapa as entrevistas e os contratos obtidos, na $2^{\mathrm{a}}$ etapa as respostas aos questionários. O quadro 3 descreve a subdivisão e os atributos de cada etapa quanto ao local, população e amostra.

Quadro 3 - Resumo da fonte primária: coleta de dados

\begin{tabular}{|c|c|}
\hline $\begin{array}{c}\mathbf{1}^{\mathbf{a}} \text { Etapa - Instrumento de Pesquisa - } \\
\text { entrevistas de Profundidade }\end{array}$ & $\mathbf{2}^{\mathbf{a}}$ Etapa - Instrumento de Pesquisa - questionário \\
\hline $\begin{array}{c}\text { Atividades: definição das empresas, } \\
\text { agendamento e realização das } \\
\text { entrevistas, de forma pessoal ou por } \\
\text { telefone. }\end{array}$ & $\begin{array}{c}\text { Atividades: definição e validação das empresas, contato com os } \\
\text { sujeitos, aplicação do questionário, análise, validação e } \\
\text { tratamento dos dados. }\end{array}$ \\
\hline \multicolumn{2}{|c|}{ Local da pesquisa: Grande São Paulo } \\
\hline $\begin{array}{c}\text { População: Todas as empresas desta } \\
\text { região, potenciais compradores de } \\
\text { serviços de BPO. }\end{array}$ & $\begin{array}{c}\text { População: Todas as empresas desta região, exceto as integrantes } \\
\text { da } 1^{\text {a }} \text { etapa e do pré-teste do questionário. }\end{array}$ \\
\hline $\begin{array}{c}\text { Amostra: } 15 \text { empresas e 16 gestores. } \\
\text { Seis gestores aceitaram participar. Os } \\
\text { demais apontaram várias razões para não } \\
\text { atender ao convite. }\end{array}$ & $\begin{array}{c}\text { Amostra: 153 empresas e 210 gestores. 23 gestores (11\%) } \\
\text { responderam totalmente o questionário; 07 de forma incompleta; } \\
13 \text { declinaram e 167 não se manifestaram. }\end{array}$ \\
\hline
\end{tabular}

Fonte: os autores. 


\section{$\underline{1^{a} \text {. Etapa: }}$}

$\mathrm{Na} 1^{\text {a }}$ etapa, houve o contato pessoal com os gestores, seguido da declaração dos objetivos da pesquisa. Nem todos aceitaram participar, pelas razões a seguir: $25 \%$ alegaram políticas corporativas impeditivas da matriz; $12,5 \%$ ausência de tempo; 18,75\% estavam em viagem ao exterior e $6 \%$ não contratam serviços na modalidade $B P O$.

O roteiro possui 23 perguntas prédefinidas, abertas e fechadas. Outras questões surgiram e os respondentes atenderam às demandas. As perguntas foram agrupadas em quatro blocos: 1 Identificação e características da Empresa; 2 - Perfil do Respondente; 3 - Serviços tomados de provedores de outsourcing; e 4

- Gestão do contrato. As respostas obtidas foram analisadas com o uso da Análise de Conteúdo (BARDIN, 2009).

\section{$\underline{2^{a} \text {. Etapa: }}$}

$\mathrm{Na} 2^{\mathrm{a}}$ etapa foi aplicado um questionário para os 210 contratantes informados no quadro 3. O questionário, com perguntas abertas e fechadas, está dividido em grupos de informações: identificação e características da empresa; perfil do respondente; identificação dos serviços administrativos e financeiros contratados junto a prestadores de serviços, características de atendimento e alçadas de decisão sobre a contratação. As assertivas foram agrupadas em quatro constructos, obtidos com a fundamentação teórica:

percepção dos gestores sobre os serviços contratados; gestão do contrato; fatores de qualidade dos serviços contratados e fatores causadores da assimetria informacional.

Usou-se a escala Likert, com 33 assertivas, medidas com variância entre discordo totalmente (1) e concordo totalmente (5), distribuídas nos quatro constructos. Foram inseridas nove assertivas negativas $(27,3 \%$ do total), buscando confirmar a confiabilidade das respostas obtidas, manter a atenção dos respondentes e evitar respostas que não condizem com a essência da temática questionada (MALHOTRA, 2006).

Houve a validação de aderência do conteúdo do questionário por um júri com três especialistas, com base em um quadro de análise dos constructos versus as assertivas. A validação teve duas etapas: (a) validação da amplitude do conteúdo; e (b) avaliação da estabilidade e da consistência do conteúdo. Foram identificadas onze variáveis, alinhadas aos objetivos perseguidos. Houve um pré-teste 
com onze sujeitos, para obter finalidade e validade do conteúdo (SELLTIZ et al., 1987). O pré-teste aumentou a compreensão sobre a percepção e entendimento dos respondentes. Esclareceu as instruções e outras comunicações sobre o conteúdo e permitiu melhorar a definição e a medição das inquirições feitas.

Os questionários foram aplicados por meio eletrônico, disponíveis para os respondentes por 60 dias. Houve uma emissão e duas retransmissões. As duas primeiras com um e-mail criado para a pesquisa e o último envio com o e-mail profissional de um autor, ambos direcionando os sujeitos a responderem o questionário na base do sistema gerenciador dos dados (questionários respondidos parcialmente; completos; total de respondidos, completos ou parciais; armazenamento dos dados; análise estatística da quantidade de respostas por tipo de perguntas entre outras).

As limitações da pesquisa são as seguintes:

a) definição da amostra: não conhecimento de todas as empresas na grande São Paulo que terceirizam atividades administrativas e financeiras. A amostra foi extraída de uma "população não conhecida", cuja caracterização não foi identificada em outros trabalhos sobre o assunto. Foram usadas várias fontes de dados para identificar as 153 empresas e 210 gestores contratantes de

b) serviços de $B P O$. Houve o contato com os gestores e / ou aqueles que cuidam de suas agendas, para saber se a empresa e / ou o gestor é contratante destes serviços;

c) setor de atividade: público ou privado. Não foram criados parâmetros de exclusão; porém, apenas uma empresa analisada é do setor público;

d) resultado da pesquisa: esperavase obter em torno de 100 questionários. Em face das dificuldades enfrentadas, a coleta foi encerrada com 23 respondentes. Existe a convicção de que a continuidade da pesquisa pode obter respostas para jogar luzes ao trabalho dos pesquisadores e demais sujeitos do segmento de $B P O$ para atividades administrativas e financeiras no Brasil. 


\section{APRESENTAÇÃO E DISCUSSÃO DOS RESULTADOS}

\subsection{Síntese do Achados da $1^{\mathrm{a}}$ Etapa}

Dos 16 gestores contatados, seis (38\%) aceitaram participar. Constatou-se que a relação entre os prestadores e contratantes é regida por um contrato balizado pela legislação comercial. Um entrevistado relatou a existência de um gestor de contratos e requer do prestador uma contraparte para que, juntos, garantam o cumprimento do contrato. A análise dos contratos revelou a falta de regras para medir o nível dos serviços, indicando a ausência de métricas para avaliar o desempenho dos prestadores e que o tempo médio da relação contratual é de cinco anos.

Os entrevistados apontaram quatro atributos para a terceirização: especialização do prestador; controle do número de funcionários dos tomadores (head count); qualidade dos serviços prestados e controle dos custos fixos dos contratantes. Declararam-se satisfeitos com os serviços recebidos, sugerindo a aceitação da terceirização. Para eles, a assimetria informacional não tem afetado de forma negativa a relação contratual. Estes resultados estimularam a continuidade da pesquisa, com uma amostra maior de empresas.

\subsection{Segunda Etapa}

4.2.1 Características dos sujeitos e das empresas

Dos 23 respondentes, 17 eram do sexo masculino e seis do feminino, idades entre 32 e 53 anos, média de 41 e desvio padrão de 6,4 anos. Quatro sujeitos ocupavam postos de sócio / diretor, 13 de controller / gerência e seis eram especialistas / contadores.

Quanto ao tempo de trabalho nas empresas, esperava-se que os sujeitos ocupassem posições com autonomia para contratar os serviços ou que no mínimo, recebessem os serviços contratados. Dez sujeitos trabalham na empresa há menos de cinco anos, nove estão há onze e quatro entre seis e dez anos.

Nove empresas são de capital nacional, doze estrangeiro e duas, misto. Uma é pública e 22 são privadas. Sete estão no segmento industrial, oito no comércio, quatro em serviços e as demais em outros setores. Cinco faturavam até $\mathrm{R} \$ 16$ milhões de reais, cinco até $\mathrm{R} \$ 90$ milhões, quatro até $\mathrm{R} \$ 300$ milhões e nove acima de $\mathrm{R} \$ 300$ milhões. Oito possuíam até 100 empregados, uma até 250 , duas até 500, uma até 1000 e 11 acima de 1.000 empregados.

\subsubsection{Identificação dos serviços e das} modalidades de atendimento 
Este item descreve os serviços administrativos e financeiros contratados junto a prestadores, as características de atendimento e alçadas de decisão para a contratação. As frequências descritas nas tabelas 1, 2 e 3 não guardam relação direta com a quantidade de 23 respondentes, pois cada sujeito pode ser contratante de todos os serviços ou de uma quantidade inferior, variável na escala de serviços, de 1 a 5 . Solicitou-se que os sujeitos informassem os serviços contratados nos últimos cinco anos e as modalidades de atendimento. Os resultados estão na tabela 1 .

Tabela 1 - Duração do contrato

\begin{tabular}{|c|c|c|c|c|c|c|c|c|}
\hline Serviços & Nunca & $\mathbf{1}$ ano & $\mathbf{2}$ anos & $\mathbf{3}$ anos & $\mathbf{4}$ anos & $\mathbf{5}$ anos & $\begin{array}{c}\text { Mais } \\
\text { de 5 } \\
\text { anos }\end{array}$ & $\begin{array}{c}\text { Não } \\
\text { sei }\end{array}$ \\
\hline 1 - Controle Contábil & 0 & 4 & 1 & 0 & 1 & 3 & 9 & 0 \\
\hline 2 - Financeiros & 11 & 1 & 0 & 0 & 1 & 0 & 4 & 2 \\
\hline 3- Tributário/Societário & 4 & 3 & 1 & 0 & 2 & 1 & 8 & 0 \\
\hline 4 - Pessoal & 7 & 0 & 1 & 0 & 1 & 1 & 5 & 2 \\
\hline 5 - Outros & 4 & 0 & 1 & 0 & 0 & 0 & 2 & 1 \\
\hline
\end{tabular}

Fonte: dados da pesquisa

Onze sujeitos afirmaram que a empresa nunca contratou serviços financeiros. Sete não contrataram serviços de atividades de pessoal. Nove empresas contratam serviços de controle contábil e oito os serviços tributários há mais de cinco anos.

A frequência apresentada na tabela

1 (17 empresas contratam serviços de

Tabela 2 - Contratação com o mesmo prestador

\begin{tabular}{c|c|c|c|c|c}
\hline \multirow{2}{*}{ Serviços } & \multirow{2}{*}{ Não se aplica } & \multirow{2}{*}{ Sim } & \multirow{2}{*}{ Não } & \multicolumn{2}{|c}{$\begin{array}{c}\text { Prestadores durante } \\
\text { o período }\end{array}$} \\
\cline { 4 - 6 } & & & & dois & três \\
\hline 1 - Controle Contábil & 1 & 13 & 2 & 0 & 3 \\
\hline 2 - Financeiros & 10 & 4 & 2 & 0 & 1 \\
\hline 3-Tributário/Societário & 4 & 10 & 1 & 0 & 4 \\
\hline 4 - Pessoal & 8 & 6 & 0 & 1 & 1 \\
\hline 5 - Outros & 5 & 2 & 0 & 0 & 1 \\
\hline
\end{tabular}

Fonte: dados da pesquisa controle contábil e serviços tributários há mais de 5 anos) pode ser confrontada com o tempo em que os respondentes trabalham nas empresas. Estes achados podem ser confrontados com o resultado da tabela 2 , que revela se os serviços contratados são com o mesmo prestador. 
Treze sujeitos afirmam que suas empresas costumam contratar o mesmo prestador para os serviços contábeis e 10 para os tributários. Quatro chegaram a contratar três prestadores para os serviços tributários durante os últimos cinco anos. Para a maioria dos respondentes, a relação contratual apresenta tendência estável entre prestador e contratante.

A tabela 3 revela as formas de atendimento pelos prestadores, para a qual não foi localizada uma definição na fundamentação teórica. As expressões “In house"; "Out house" e "Mix" integram o jargão do segmento de terceirização. "In house" é o atendimento e prestação dos serviços pela execução das atividades contratadas de contabilidade, fiscal, folha de pagamento, entre outras, dentro da prestadora. "Out house" é a execução das atividades dentro da contratante. No "Mix" a prestação dos serviços ocorre nos dois ambientes, quando algumas atividades são executadas internamente e outras externamente, da prestadora dos serviços.

Tabela 3 - Forma de atendimento pelos prestadores de serviços

\begin{tabular}{c|c|c|c|c|c|c|c|c|c}
\hline \multirow{2}{*}{ Serviços } & \multicolumn{3}{|c|}{$\begin{array}{c}\text { No ambiente do prestador } \\
\text { in house }\end{array}$} & \multicolumn{2}{c|}{$\begin{array}{c}\text { No ambiente do } \\
\text { contratante - out } \\
\text { house }\end{array}$} & \multicolumn{3}{c}{$\begin{array}{c}\text { Em ambos os locais - } \\
\text { mix }\end{array}$} \\
\cline { 2 - 13 } & $\begin{array}{c}\text { Não se } \\
\text { aplica }\end{array}$ & Sim & Não & $\begin{array}{c}\text { Não se } \\
\text { aplica }\end{array}$ & Sim & Não & $\begin{array}{c}\text { Não se } \\
\text { aplica }\end{array}$ & Sim & Não \\
\hline Controle Contábil & 5 & 9 & 3 & 5 & 8 & 4 & 7 & 7 & 3 \\
\hline Financeiros & 10 & 4 & 3 & 11 & 4 & 2 & 11 & 1 & 4 \\
\hline Tributário/Societário & 6 & 7 & 5 & 6 & 8 & 4 & 10 & 4 & 3 \\
\hline Pessoal & 8 & 5 & 1 & 8 & 3 & 4 & 9 & 3 & 2 \\
\hline Outros & 7 & 1 & 0 & 7 & 1 & 0 & 6 & 2 & 0 \\
\hline
\end{tabular}

Fonte: dados da pesquisa.

Nove pessoas afirmaram que a prestadora realiza os serviços contábeis em seu ambiente de trabalho. Oito afirmaram que a prestadora costuma realizar os serviços contábeis ou tributários na empresa contratante. Sete pessoas afirmaram que a prestadora realiza os serviços contábeis na prestadora e na contratante.
Quanto à decisão de contratação dos serviços na modalidade de $B P O$, dois respondentes informaram decidir sozinhos para contratar o prestador. A maioria (12) informou que a decisão cabe a um comitê formado por vários agentes da organização e nove informaram que a decisão é tomada em conjunto com a diretoria. 


\subsubsection{Análise de clusters}

Foi realizada uma análise de clusters (AC) com as questões 1 a 33 do questionário. A AC é uma técnica multivariada usada para detectar grupos homogêneos nos dados (no caso, os sujeitos). Os objetos em cada cluster tendem a ser semelhantes entre si e distintos de objetos de outros clusters. (HAIR JR. et al., 2005; PESTANA; GAGEIRO, 2000).

Um passo da técnica é escolher uma forma de medir a distância entre pares de casos usando os valores observados nas variáveis, visando avaliar semelhanças ou diferenças nos casos analisados. Escolheuse como medida de semelhança a distância euclidiana quadrática, aplicável a esta pesquisa 2006; PESTANA; GAGEIRO, 2000).

Foram testados sete métodos de aglomeração hierárquicos, pois não havia um número de clusters determinado a priori. A intenção de avaliar os resultados por métodos hierárquicos é explorar os dados e verificar quantos clusters devem ser retidos. O método de Ward, que minimiza o quadrado da distância euclidiana às médias dos aglomerados, combinando clusters com poucas observações, mostrou boa separação entre os clusters (HAIR JR. et al., 2005).
Apresenta-se a seguir os resultados encontrados.

Não há critério estatístico aplicável para definir a quantidade de clusters, o que deixa a cargo do pesquisador definir esses critérios. Procurou-se por clusters com grande homogeneidade entre si. Quando a junção de dois clusters implica em diminuir a homogeneidade, adota-se a solução anterior. Isso é visualizado no dendrograma gerado, não demonstrado por questões de espaço, que ofereceu a imagem de dois clusters, os quais formaram agrupamentos de sujeitos distintos. $\mathrm{O}$ primeiro com 17 sujeitos, $(1,2,6,8$ a 19 , 22 e 23), o segundo com seis $(3,4,5,7,20$ e 21).

Buscou-se verificar se os dois clusters possuem opiniões distintas. Iniciou-se com o teste de Shapiro-Wilks (SW), para verificar se as 33 variáveis da escala Likert são normais (MALHOTRA, 2006). Este teste foi usado para verificar se havia diferenças entre os clusters.

O teste de SW revelou que todas as assertivas apresentam significância inferior a 0,05 , ou seja, nenhuma das variáveis pode ser considerada normal. Assim, usose o teste não paramétrico de MannWhitney (MW) para determinar quais variáveis são discriminadoras. $\mathrm{O}$ resultado está na tabela 4. 
Análise do grau de satisfação dos contratantes de serviços terceirizados na modalidade BPO - Business Process Outsourcing - na Grande São Paulo

Tabela 4 - Resultados do Teste de Mann-Whitney por assertivas

\begin{tabular}{|c|c|c|c|c|c|c|c|c|c|c|}
\hline \multirow{2}{*}{ Constructos } & \multirow{2}{*}{ Assertivas } & \multicolumn{3}{|c|}{ Cluster 1} & \multicolumn{3}{|c|}{ Cluster 2} & \multirow{2}{*}{$\begin{array}{c}\text { M-W } \\
\mathbf{U}\end{array}$} & \multirow{2}{*}{$\mathbf{Z}$} & \multirow{2}{*}{ Sig. } \\
\hline & & D & I & $\mathbf{C}$ & D & I & $\mathbf{C}$ & & & \\
\hline \multirow{12}{*}{$\begin{array}{c}1 \text { - percepção } \\
\text { dos gestores } \\
\text { sobre os } \\
\text { serviços } \\
\text { contratados }\end{array}$} & \multirow{2}{*}{$\begin{array}{l}\text { 2. Os serviços são } \\
\text { executados por profissionais } \\
\text { tecnicamente preparados }\end{array}$} & 1 & 3 & 13 & 6 & 0 & 0 & \multirow{2}{*}{3,000} & \multirow{2}{*}{$-3,569$} & \multirow{2}{*}{,000 } \\
\hline & & $6 \%$ & $18 \%$ & $76 \%$ & $100 \%$ & $0 \%$ & $0 \%$ & & & \\
\hline & \multirow{2}{*}{$\begin{array}{l}\text { 5. a qualidade do serviço } \\
\text { prestado é compatível com } \\
\text { as exigências da contratante }\end{array}$} & 1 & 2 & 14 & 6 & 0 & 0 & \multirow{2}{*}{2,000} & \multirow{2}{*}{$-3,577$} & \multirow{2}{*}{, 000} \\
\hline & & $6 \%$ & $12 \%$ & $82 \%$ & $100 \%$ & $0 \%$ & $0 \%$ & & & \\
\hline & \multirow{2}{*}{$\begin{array}{l}\text { 6. o prestador aplica as } \\
\text { mudanças da legislação }\end{array}$} & 2 & 0 & 15 & 2 & 1 & 3 & \multirow{2}{*}{22,000} & \multirow{2}{*}{$-2,191$} & \multirow{2}{*}{,028 } \\
\hline & & $12 \%$ & $0 \%$ & $88 \%$ & $33 \%$ & $17 \%$ & $50 \%$ & & & \\
\hline & \multirow{2}{*}{$\begin{array}{l}\text { 7. a equipe do prestador é } \\
\text { confiável }\end{array}$} & 0 & 3 & 14 & 4 & 0 & 2 & \multirow{2}{*}{23,000} & \multirow{2}{*}{$-2,093$} & \multirow{2}{*}{,036 } \\
\hline & & $0 \%$ & $18 \%$ & $82 \%$ & $67 \%$ & $0 \%$ & $33 \%$ & & & \\
\hline & \multirow{2}{*}{$\begin{array}{c}\text { 8. o serviço prestado está de } \\
\text { acordo com o pactuado no } \\
\text { contrato }\end{array}$} & 1 & 3 & 13 & 4 & 0 & 2 & \multirow{2}{*}{19,000} & \multirow{2}{*}{$-2,396$} & \multirow{2}{*}{,017 } \\
\hline & & $6 \%$ & $18 \%$ & $76 \%$ & $67 \%$ & $0 \%$ & $33 \%$ & & & \\
\hline & \multirow{2}{*}{$\begin{array}{l}\text { 9. há pontualidade na } \\
\text { entrega dos serviços } \\
\text { prestados }\end{array}$} & 1 & 2 & 14 & 6 & 0 & 0 & & & \\
\hline & & $6 \%$ & $12 \%$ & $82 \%$ & $100 \%$ & $0 \%$ & $0 \%$ & , 500 & $-3,772$ &, 000 \\
\hline & 14. o prestador cumpre suas & 0 & 3 & 14 & 1 & 1 & 4 & 2350 & 2057 & 040 \\
\hline & obrigações legais & $0 \%$ & $18 \%$ & $82 \%$ & $17 \%$ & $17 \%$ & $67 \%$ & 25,300 & $-2,031$ & , \\
\hline 2 - gestão do & $\begin{array}{l}\text { 16. sempre há gestores do } \\
\text { contrato claramente }\end{array}$ & 3 & 2 & 12 & 2 & 2 & 2 & $400 \Omega$ & 56 & 050 \\
\hline $\begin{array}{l}\text { prestação de } \\
\text { serviços }\end{array}$ & $\begin{array}{l}\text { indicados pelo contratante e } \\
\text { pelo prestador }\end{array}$ & $18 \%$ & $12 \%$ & $71 \%$ & $33 \%$ & $33 \%$ & $33 \%$ & & & \\
\hline & 18. os gestores da & 1 & 1 & 15 & 4 & 0 & 2 & & & \\
\hline & $\begin{array}{l}\text { contratante supervisionam as } \\
\text { atividades dos terceirizados }\end{array}$ & $6 \%$ & $6 \%$ & $88 \%$ & $67 \%$ & $0 \%$ & $33 \%$ & 16,000 & $-2,718$ & ,007 \\
\hline & $\begin{array}{l}\text { 19. o contratante e o } \\
\text { prestador possuem os } \\
\text { mesmos parâmetros de }\end{array}$ & 2 & 4 & 11 & 5 & 0 & 1 & 14,500 & $-2,700$ & ,007 \\
\hline & $\begin{array}{c}\text { qualidade para os serviços } \\
\text { prestados }\end{array}$ & $12 \%$ & $24 \%$ & $65 \%$ & $29 \%$ & $0 \%$ & $17 \%$ & & & \\
\hline & & 2 & 3 & 12 & 6 & 0 & 0 & & & \\
\hline $\begin{array}{l}3 \text { - fatores de } \\
\text { qualidade dos }\end{array}$ & $\begin{array}{l}\text { sempre cumpridos } \\
\text { semo }\end{array}$ & $12 \%$ & $18 \%$ & $71 \%$ & $35 \%$ & $0 \%$ & $0 \%$ & 3,000 & $-3,534$ & ,000 \\
\hline $\begin{array}{l}\text { Serviços } \\
\text { contratados }\end{array}$ & 23. o prestador é hábil para & 3 & 3 & 11 & 5 & 0 & 1 & & & \\
\hline & solicitações do contratante & $18 \%$ & $18 \%$ & $65 \%$ & $29 \%$ & $0 \%$ & $17 \%$ & 10,500 & $-2,303$ & - \\
\hline & $\begin{array}{l}\text { 24. a dedicação do prestador } \\
\text { na realização dos serviços }\end{array}$ & 3 & 2 & 12 & 5 & 0 & 1 & & & \\
\hline & $\begin{array}{c}\text { deixa o contratante } \\
\text { confortável }\end{array}$ & $18 \%$ & $12 \%$ & $71 \%$ & $29 \%$ & $0 \%$ & $17 \%$ & & & \\
\hline $\begin{array}{c}4 \text { - fatores } \\
\text { causadores da } \\
\text { assimetria }\end{array}$ & $\begin{array}{l}\text { 28. não cabe ao contratante } \\
\text { estabelecer padrões para a }\end{array}$ & 12 & 1 & 4 & 6 & 0 & 0 & 21,000 & $-2,245$ & ,025 \\
\hline informacional & & $71 \%$ & $6 \%$ & $24 \%$ & $100 \%$ & $0 \%$ & $0 \%$ & & & \\
\hline
\end{tabular}

Fonte: dados da pesquisa. 
A significância do teste de MW foi inferior a 0,05 para 14 assertivas, nas quais os clusters possuem opiniões distintas. Para analisar mais detalhadamente as opiniões dos sujeitos sobre as questões que apresentaram diferenças, realizou-se a análise por constructo, considerando conjuntamente as opções da escala Likert, agora com três agrupamentos (discordo, não concordo nem discordo e discordo), apresentada e discutida a seguir.

\section{Primeiro constructo}

Os sujeitos do cluster 1 tendem a concordar que os serviços são executados por profissionais tecnicamente preparados (assertiva 2), estão de acordo com o pactuado no contrato (assertiva 8), há pontualidade na entrega (assertiva 9), a qualidade é compatível com as exigências da contratante (assertiva 5) e a equipe do prestador de serviços é confiável (assertiva 7), já os sujeitos do cluster 2 tendem a discordar. A proporção de concordância na assertiva 6 (o prestador dos serviços aplica as mudanças da legislação) é maior no cluster 1 .

O resultado demonstrado na tabela 4 revela que alguns critérios de avaliação da qualidade e de competitividade (competência técnica; credibilidade e segurança; custo versus tempo gasto e tempo de resposta) na prestação dos serviços debatidos na fundamentação teórica (GIANESI; CORRÊA, 1994), são atendidos e contribuem para a percepção positiva dos contratantes em relação aos prestadores de serviços.

\section{Segundo constructo}

A proporção de concordância quanto ao cumprimento das obrigações legais pelo prestador (assertiva 14) é maior no cluster 1 . O cluster 2 tende a discordar que os gestores da contratante supervisionam as atividades dos terceirizados (assertiva 18), já o cluster 1 tende a concordar. O cluster 1 tende a concordar que sempre há gestores do contrato claramente indicados pelo contratante e pelo prestador (assertiva 16), mas parece não haver um consenso no cluster 2.

Para Whinston, Barua e Mani (2007) as estruturas de governança hierárquica fornecem um quadro integrador entre prestador e contratante. Isto ajuda a conhecer as diferenças, superar os conflitos de interesse individuais e facilitar a adaptação do processo de terceirização. Tudo isto só será possível se houver como alicerce da relação, o contrato de prestação de serviços consensado entre as partes. 


\section{Terceiro constructo}

O cluster 1 tende a concordar com as assertivas 19 (o contratante e o prestador possuem os mesmos parâmetros de qualidade para os serviços prestados), 22 (os prazos pactuados são sempre cumpridos), 23 (o prestador é hábil para responder prontamente as solicitações do contratante) e 24 (a dedicação do prestador na realização dos serviços deixa o contratante confortável), já o cluster 2 tende a discordar.

\section{Quarto constructo}

$\mathrm{Na}$ assertiva 28 (não cabe ao contratante estabelecer padrões para a prestação dos serviços) verifica-se que os seis sujeitos do cluster 2 tendem a discordar, enquanto que no cluster 1 alguns concordam, porém 12 respondentes discordam. Desta forma, após a análise realizada, é possível caracterizar os dois clusters da forma a seguir descrita.

\section{Cluster 1 - Satisfeitos}

Os sujeitos deste cluster crêem que os serviços são executados por profissionais tecnicamente preparados (assertiva 2), estão de acordo com o pactuado no contrato (assertiva 8), há pontualidade na entrega (assertiva 9), a qualidade é compatível com as exigências da contratante (assertiva 5), a equipe do prestador é confiável (assertiva 7) e o prestador aplica as mudanças da legislação (assertiva 6)

Concordam que o prestador cumpre suas obrigações legais (assertiva 14), que os gestores da contratante supervisionam as atividades dos terceirizados (assertiva 18) e que sempre há gestores do contrato claramente indicados pelo contratante e pelo prestador (assertiva 16).

Afirmam que o contratante e o prestador possuem os mesmos parâmetros de qualidade para os serviços prestados (assertiva 19), os prazos pactuados são sempre cumpridos (assertiva 22), o prestador é hábil para responder prontamente as solicitações (assertiva 23) e a dedicação do prestador na realização dos serviços deixa o contratante confortável (assertiva 24). Além disso, concordam que cabe ao contratante estabelecer padrões para a prestação dos serviços (assertiva 28).

Este resultado está alinhado com a fundamentação teórica sobre serviços (GRÖNROOS, 2004; KOTLER; BLOOM, 1988; LOVELOCK; WRIGHT, 2001; NORMANN, 1993) e sobre o comportamento do cliente em relação às suas expectativas enquanto contratante dos serviços, pois, segundo Mani, Barua e 
Whinston (2005), este espera do prestador confiabilidade, receptividade, responsabilidade, e sistematização.

\section{Cluster 2 - Insatisfeitos}

Os sujeitos deste cluster não crêem que os serviços são executados por profissionais tecnicamente preparados (assertiva 2), os serviços não estão de acordo com o pactuado no contrato (assertiva 8), não há pontualidade na entrega (assertiva 9), a qualidade não é compatível com as exigências da contratante (assertiva 5), a equipe do prestador não é confiável (assertiva 7), mas o prestador aplica as mudanças da legislação (assertiva 6).

Concordam que o prestador cumpre suas obrigações legais (assertiva 14), mas afirmam que os gestores da contratante não supervisionam as atividades dos terceirizados (assertiva 18). Também não há um consenso acerca da assertiva 16 (sempre há gestores do contrato claramente indicados pelo contratante e pelo prestador).

Afirmam que o contratante e o prestador não possuem os mesmos parâmetros de qualidade para os serviços prestados (assertiva 19), os prazos pactuados nem sempre são cumpridos (assertiva 22), o prestador não é hábil para responder prontamente as solicitações (assertiva 23) e a dedicação do prestador na realização dos serviços não deixa o contratante confortável (assertiva 24). Por outro lado, concordam que cabe ao contratante estabelecer padrões para a prestação dos serviços (assertiva 28).

A seguir, verifica-se se os clusters apresentam diferenças nas respostas às questões iniciais do instrumento de pesquisa.

\subsubsection{Perfil dos clusters - características dos sujeitos e das empresas}

Analisou-se o perfil dos dois clusters, com base em suas respostas às questões iniciais do questionário. Foi preciso verificar se há correlação entre os clusters e as variáveis analisadas são mensuradas ao nível nominal; assim, usouse a correlação V de Cramer, indicada nesta situação (LEVIN; FOX, 2004). Não se usou o teste qui-quadrado pois, devido ao número de respondentes, houve muitas frequências esperadas com valores inferiores a 5, o que desaconselha o seu uso. Foram usadas as empresas de capital nacional e estrangeiro, exceto as de capital misto, por serem estas em número baixo para a realização do teste. As empresas foram divididas em três grupos: com até 249 empregados, de 250 a 999 e acima de 1000 empregados. A tabela 5 mostra os valores destas correlações para as questões iniciais. 
Tabela 5 - correlação entre os clusters e as questsões iniciais

\begin{tabular}{c|c|c}
\hline Questões & Correlação & Significância \\
\hline Sexo &,- 127 &, 541 \\
\hline Tempo de trabalho na empresa &, 081 &, 927 \\
\hline Origem do capital &,- 091 &, 676 \\
\hline Segmento de mercado &, 214 &, 789 \\
\hline Faturamento anual no Brasil &, 508 &, 114 \\
\hline Número de empregados &, 440 &, 108 \\
\hline
\end{tabular}

Fonte: dados da pesquisa.

A significância da correlação apresentou valor superior a 0,05 para todas as questões, indicando que os clusters possuem o mesmo perfil nestas variáveis.

Para verificar se há diferenças de opinião por conta da idade entre os sujeitos dos clusters usou-se o teste $\mathrm{t}$, pois a variável idade possui distribuição normal (pelo teste de SW, ao nível de significância de 0,05$)$. O teste $t$ resultou no valor de 1,302 com 21 graus de liberdade e significância de 0,207, indicando que os clusters não possuem diferenças de opinião por conta da idade de seus componentes.

\section{CONSIDERAÇÕES FINAIS}

Buscou-se analisar qual é a percepção dos gestores de empresas sediadas na grande São Paulo, sobre os serviços administrativos e financeiros por elas contratados de organizações de serviços de terceirização na modalidade business process outsourcing (BPO)? O objetivo geral era analisar as percepções destes gestores sobre a prestação dos referidos serviços.

A resposta à questão e o alcance do objetivo requereram quatro rotas de investigação: (a) a percepção dos gestores, o grau de satisfação quanto aos serviços contratados; (b) os fatores de qualidade percebidos pelos contratantes; (c) a forma de gestão do contrato pelas partes; e (d) a existência de fatores causadores de assimetria informacional entre as partes.

Os respondentes foram agrupados em dois clusters distintos: o primeiro com 17 sujeitos (1, 2, 6, 8 a 19, 22 e 23); o segundo com seis $(3,4,5,7,20$ e 21$)$. Os dois clusters possuem opiniões distintas nas 14 assertivas demonstradas na tabela 4 . O cluster 1 foi denominado satisfeito e o cluster 2, insatisfeito.

Quanto à qualidade dos serviços prestados e a percepção dos clientes, afetada por fatores externos (experiências passadas; experiências pessoais; entre outros fatores), tem-se que:

a) construto $1-74 \%$ por cento dos respondentes manifestou satisfação quanto aos serviços contratados (cluster $1=17 / 23)$; 
b) construto 2 - a gestão do contrato pelas partes - os respondentes concordam que há gestão de contratos por ambos os lados. Há discordância em relação à fundamentação teórica (GIOSA, 2005);

c) Construto 3 - os fatores de qualidade dos serviços percebidos pelos tomadores quatro assertivas permitiram caracterizar os fatores de qualidade e em todos eles os respondentes concordam quanto ao desempenho do prestador. As assertivas tratam de aspectos técnicos, prazos de entrega, confiabilidade e cumprimento do quanto contratado. Em contra ponto, rebatem a fundamentação teórica sobre assimetria informacional.

TILLEY (2001) aponta que as empresas contratantes de serviços terceirizados na Austrália dizem que a “defasagem de experiência e de habilidades em gerenciar $\mathrm{o}$ processo" são os maiores propulsores dos problemas com a terceirização;

d) Construto 4 - a existência de fatores causadores de assimetria informacional entre as partes - há uniformidade dos respondentes, pois todo o cluster 2 discorda, enquanto 12 sujeitos do cluster 1 também discordam. Os clusters concordam que cabe ao contratante estabelecer os padrões para a prestação dos serviços.

Os resultados obtidos preencheram parte da lacuna sobre estudos para avaliar o grau de relacionamento entre contratantes e contratados de serviços administrativos financeiros e estimulam a continuidade das pesquisas. Sugerem-se outras investigações em torno da governança sobre a prestação de serviços na modalidade BPO, em especial sobre o amadurecimento das experiências vividas entre clientes e prestadores. Espera-se que os resultados obtidos estimulem os pesquisadores a

investigar outros interesses dos usuários e envolvidos na terceirização de serviços administrativos e financeiros.

\section{REFERÊNCIAS}

AKERLOF, G. A. The market for "lemons": quality uncertainty and the market mechanism. The Quarterly Journal of Economics, Cambridge, v. 84, n. 3, p. 488-500, Aug. 1970.

ALVAREZ, M. S. B. Terceirização: parceria e qualidade. Rio de Janeiro: Campos, 1996. 
ARGYRES, N.; MAYER, K. Contract design as a firm capability: an integration of learning and transaction cost perspectives. Academy of Management Review, Briarcliff Manor, v. 32, n. 4, p. 1060-1077, 2007. Disponível em: <www.ccc.cc>. Acesso em: 20 nov.

BANDEIRA, R. A. M.; MELLO, L. C. B. B.; MAÇADA, A. C. G. Elementos de flexibilidade em contratos de terceirização logística: o caso de uma empresa de telecomunicações. Produção, São Paulo, v. 22, n. 2, p. 237-248, mar./abr. 2012.

Disponível em: <http://www.scielo.br/pdf/prod/v22n2/aop _200904056.pdf >. Acesso em: 20 nov. 2012.

BARDIN, L. Análise de conteúdo. Tradução de Luís Antero Reto e Augusto Pinheiro. Lisboa: Edições 70, 2009.

BERRY, L. L. Services marketing is different. Business, Atlanta, v. 30, n. 3, p. 24, May/June 1980.

\section{BRASIL. Constituição da República} Federativa do Brasil de 1988. Disponível em:

<http://www.senado.gov.br/legislacao/cons t/con1988/CON1988_04.02.2010/art_170_ .shtm>. Acesso em: 20 nov. 2012.

Supremo Tribunal do Trabalho.

Súmula no. 331. Contrato de prestação de serviços. Legalidade (Revisão da Súmula no 256 - Res. 23/1993, DJ 21 de

28.12.1993 e 04.01.1994 1994 - Alterada (Inciso IV) - Res. 96/2000, DJ 18, $19 \mathrm{e}$ 20.09.2000 - Mantida - Res. 121/2003, DJ 19, 20 e 21.11.2003. Nov. 2003.

Disponível em:

$<$ http://www3.tst.jus.br/jurisprudencia/Su mulas_com_indice/Sumulas_Ind_301_350. html\#SUM-331>. Acesso em: 20 nov. 2012.

BROWN, D.; WILSON, S. The black book of outsourcing: how to manage the changes, challenges, and opportunities. New Jersey: John Wiley \& Sons, 2005.

\section{DRUCKER, P. Administrando em} tempos de grandes mudanças. São Paulo: Pioneira, 1999.

\section{FONSECA, J. B. L. Cláusulas abusivas} nos contratos. 2. ed. Rio de Janeiro: Forense, 1995.

FRIEDMAN, T. L. The world is flat: a brief history of the twenty-first century. Tradução [da ed. atualizada e ampliada] Cristina Serra, Sergio Duarte e Bruno Cassoti. Rio de Janeiro: Objetiva, 2007.

GÂRLEANU, N.; PEDERSEN, L. H. Adverse selection and the required return. The Review of Financial Studies, Oxford, v. 17, n. 03, p. 643-665, Aug. 2003.

GIANESI, I. G. N.; CORREA, H. L. Administração estratégica de serviços. São Paulo, Atlas, 1994.GIOSA, L. A. Terceirização: uma abordagem estratégica. São Paulo: Pioneira, 1997.

\section{GREAVER II, M. F. Strategic}

outsourcing: A structured approach to outsourcing decisions and iniciatives. New York: Amacom, 1999.

\section{GRÖNROOS, C. Marketing:}

gerenciamento e serviços. Rio de Janeiro: Campus, 2004.

HAIR JR., J. et al. Fundamentos de métodos de pesquisa em administração. Tradução: Lene Belon Ribeiro. Porto Alegre: Bookman, 2005.

HENDRIKSEN, E. S.; VAN BREDA, M. F. Teoria da contabilidade. Tradução de Antonio Zoratto Sanvicente. São Paulo: Atlas, 1999. 
HILL, M. M.; HILL, A. Investigação por questionário. 2. ed. Lisboa: Sílabo, 2005.

IBGE. Pesquisa anual de serviços. Rio de Janeiro: [S.n.], 2006. v. 8.

IDG NOW. Brasil sobe de $10^{\circ}$ para $5^{\circ}$ lugar como destino global para outsourcing: estudo da A.T. Kearney mostra que país avançou cinco posições de 2005 a 2007; mercado de terceirização vai gerar US\$ 101 bi em 2009. São Paulo, 16 de abril de 2009. Disponível em:

$<$ http://idgnow.uol.com.br/ticorporativa/2009/04/16/brasil-sobe-de10o-para-5o-lugar-como-destino-globalpara-outsourcing/\#\&panel2-1>. Acesso em: 01 nov. 2009.

JENSEN, M. C; MECKLING, W. H. A theory of the firm: governance, residual claims and organizational forms. Journal of Financial Economics, Amsterdam, v. 3, n. 4, p. 305-360, Oct. 1976.

KOTLER, P.; BLOOM, P. N. Marketing para serviços profissionais. Tradução de Auriphebo Berrance Simões. São Paulo: Atlas, 1988.

\section{LEVIN, J.; FOX, J. C. Estatística} aplicada às ciências humanas. São Paulo: Pearson Education, 2004.

LOPES, A. B. A teoria dos contratos, governança corporativa e contabilidade. In: IUDÍCIBUS, S.; LOPES, A. B. (Coord.). Teoria avançada da contabilidade. São Paulo: Atlas, 2004. p. 171-185.

LOVELOCK, C.; WRIGHT, L. Serviços: marketing e gestão. Tradução de Cid Knipel Moreira. São Paulo: Saraiva, 2001.

LUCIANO, E. M.; TESTA, M. G. Controles de governança de tecnologia da informação para a terceirização de processos de negócio: uma proposta a partir do COBIT. Journal of Information Systems and Technology Management (Online), São Paulo, v. 8, n. 1, p. 237-262,
2011. Disponível em: <http://www.scielo.br/pdf/jistm/v8n1/a12v 8n1.pdf>. Acesso em: 22 nov. 2012.

MALHOTRA, N. K. Pesquisa de marketing: uma orientação aplicada. 4. ed. Porto Alegre: Bookmam, 2006.

MANI, D.; BARUA, A.; WHINSTON, A. Of governance and the BPO Paradox: the impact of information capabilities on service satisfaction. In:

INTERNATIONAL CONFERENCE ON INFORMATION SYSTEMS (ICIS), 26., 2005, Las Vegas. Proceedings... Illinois: Association for Information Systems AIS, 2005. Paper 10. p. 109-122.

MARCELINO, P.; CAVALCANTE, S. Por uma definição de terceirização.

Caderno CRH, Salvador, v. 25, n. 65, p. 331-346, ago. 2012. Disponível em: <http://www.scielo.br/pdf/ccrh/v25n65/v2 5n65a10.pdf $>$. Acesso em: 20 nov. 2012.

MARTINS, S. P. A terceirização e o Direito do Trabalho. 7. ed. São Paulo: Atlas, 2005.

\section{NORMANN, R. Administração de} serviços: estratégia e liderança na empresa de serviços. Tradução de Ailton Bomfim Brandão. São Paulo: Atlas, 1993.

NOSSA, V.; KASSAI, J. R.; KASSAI, S. A teoria do agenciamento e a contabilidade. In: ENCONTRO DA ASSOCIAÇÃO NACIONAL DOS PROGRAMAS DE PÓS-GRADUAÇÃO EM ADMINISTRAÇÃO (ENANPAD), 24., 2000, Florianópolis. Anais... Florianópolis: ANPAD, 2000. 1 CD-ROM.

OLIVEIRA, M. Terceirização: estruturas e processos em xeque nas empresas. São Paulo: Nobel, 1994.

PAGNONCELLI, D. Terceirização e parceirização: estratégias para o sucesso empresarial. Rio de Janeiro: D.

Pagnoncelli, 1993. 
PAIVA, J. A.; SOUZA, F. M. C. Modelo de contrato de terceirização de manutenção: uma abordagem principalagente. Produção, São Paulo, v. 22, n. 4, p. 796-806, set./dez. 2012. Disponível em: <http://www.scielo.br/pdf/prod/v22n4/aop _t6_0006_0248.pdf>. Acesso em: 20 nov. 2012.

PAULY, M. V. Overinsurance and public provisiono of insurance: the roles of moral hazard and adverse selection. The

Quarterly Journal of Economics, Cambridge, v. 88, n. 1, p. 44-62, Feb. 1974.

PESTANA, M. H.; GAGEIRO, J. N. Análise de dados para ciências sociais: a complementariedade do SPSS. 2. ed. Lisboa: Silabo, 2000.

RIPERT, G. O regimento democrático e o direito civil moderno. Tradução de J. Cortezão. São Paulo: Saraiva, 1937.

SÁ, M. P.; BOMTEMPO, J. V.; QUENTAL, C. Terceirização no processamento final da indústria farmacêutica e veterinária. Revista de Administração Contemporânea, Curitiba, v. 2, n. 2, p. 85-101, maio/ago. 1998. Disponível em: <http://www.scielo.br/pdf/rac/v2n2/v2n2a0 6.pdf>. Acesso em: 20 nov. 2012.

SELLTIZ, C. et al. Métodos de pesquisa nas relações sociais: delineamentos de pesquisa. 2. ed. São Paulo: E.P.U., 1987. v. 1.

\footnotetext{
SINDICATO DAS EMPRESAS DE PRESTAÇÃO DE SERVIÇOS A TERCEIROS, COLOCAÇÃO E ADMINISTRAÇÃO DE MÃO-DE-OBRA E DE TRABALHO TEMPORÁRIO NO ESTADO DE SÃO PAULO SINDEPRESTEM. Pesquisa setorial 2007/2008: dados e informações do setor de trabalho temporário e de serviços terceirizáveis no Brasil. [2008]. Disponível em:
}

<http://www.sindeprestem.com.br/v2/cms/ UserFiles/File/PesquisaSetorial_sitepublic o.pdf>. Acesso em: 20 nov. 2012.

SOUZA, L. L. C.; MALDONADO, M. U.; RADOS, G. J. V. Gestão da terceirização no setor brasileiro de distribuição de energia elétrica. RAE-Revista de Administração de Empresas, São Paulo, v. 51, n. 2, p. 188-201, mar./abr. 2011. Disponível em: <http://www.scielo.br/pdf/rae/v51n2/v51n 2a06.pdf>. Acesso em: 20 nov. 2012.

SPENCE, A.M. Job market signaling. Quarterly Journal of Economics, Cambridge, v. 87, n. 3, p. 355-374, Aug. 1973.

STIGLITZ, J. E.; WEISS, A. Credit rationing in markets with imperfect information. American Economic Review, Nashville, v. 71, n. 3, p. 393-410, June 1981.

TILLEY, K. Weighing benefits of outsourcing. Business Insurance, Chicago, v. 35, n. 24, p. 23-24, June 2001.

VIDAL NETO, P. Aspectos jurídicos da terceirização. Revista de Direito de Trabalho, São Paulo, n. 80, p. 23-30, 1992.

WHINSTON, A.; BARUA, A.; MANI, D. Conflict resolution or informational response? An empirical analysis of the determinants of governance choice in business process outsourcing relationships. In: INTERNATIONAL CONFERENCE ON INFORMATION SYSTEMS (ICIS), 28., 2007, Montreal. Proceedings... Illinois: Association for Information Systems - AIS, 2007. p. 1-17. 